\title{
Habilidades Sociais e Variáveis Sociodemográficas em Crianças com Idade Escolar: Um Estudo Descritivo
}

\author{
Letícia dos Santos Van Grol \\ Ilana Andretta ${ }^{1}$ \\ Programa de Pós-Graduação em Psicologia da Universidade do Vale do Rio dos Sinos, \\ São Leopoldo, RS, Brasil
}

\begin{abstract}
Resumo
A infância é um período importante para a aquisição e desenvolvimento de habilidades sociais e, os prejuízos nesta área estão relacionados também a dificuldades de relacionamentos interpessoais. Este estudo teve como objetivo identificar quais as habilidades sociais presentes em crianças inseridas no contexto escolar e mensurar a relação com variáveis sociodemográficas. Para avaliar habilidades sociais, utilizou-se o Inventário Multimídia de Habilidades Sociais para Crianças - IMHSC-Del Prette (2005) além de um questionário para avaliação de dados sociodemográficos. Participaram deste estudo 100 crianças com idades entre 07 e 14 anos do $1^{\circ}$ ao $5^{\circ}$ ano do ensino fundamental de um município do interior do Rio Grande do Sul. Os resultados evidenciaram diferença significativa entre os sexos na média geral dos itens avaliados. Os resultados indicam uma trajetória de expansão das habilidades sociais, visto que os participantes com 10 anos ou mais demonstraram ser mais habilidosos socialmente que os participantes de 7 anos. Sendo assim, os resultados obtidos com esse trabalho ressaltam a importância das habilidades sociais na infância, pois o desenvolvimento das mesmas pode atuar como fator de proteção ao desenvolvimento psicossocial das crianças.
\end{abstract}

Palavras-chave: Habilidades sociais, infância, prevenção.

\section{Social Skills and Sociodemographic Variables in School Age Children: A Descriptive Study}

\begin{abstract}
Childhood is an important period for the acquisition and development of social skills and the deficits in this area are related to inappropriate behaviors, poor school performance and difficulties in interpersonal relationships. This study aims to identify the social skills' children in the school context and measure the relationship with sociodemographic variables. To evaluate social skills was used the Inventory System of Social Skills for Children (Inventário Multimídia de Habilidades Sociais para Crianças - IMHSC-Del Prette) as well as a questionnaire to assess sociodemographic data. Participated in this study 100 children from 07 to 14 years old from elementary school of a city in the interior of Rio Grande do Sul/ RS. The results indicate a trajectory of expansion of social skills, as the participants aged 10 years or more have proved more socially skilled than 7 years-old children. Therefore, this study's results highlight the importance of social skills during childhood from the perspective that the presence of these skills may act as a protective factor during child development.
\end{abstract}

Keywords: Social skills, childhood, prevention.

Endereço para correspondência: Rua Onório Silveira Dias, 1483, 1601, Bairro: São João, Porto Alegre, RS, Brasil 90540-070. E-mail: leticia_vangrol@hotmail.com e ilana.andretta@gmail.com 


\section{Habilidades Sociales y las Variables Sociodemográficas en Niños con Edad Escolar: Estudio Descriptivo}

\section{Resumen}

La infancia es un periodo importante para la adquisición y desarrollo de habilidades sociales y los prejuicios en esta área están también y la dificultad en las relaciones interpersonales. Este estudio tiene como objetivo identificar las habilidades sociales presentes en los niños insertados en el contexto escolar y medir la relación con variables sociodemográficas. Para evaluar las habilidades sociales, se utilizó un inventario multimedia de habilidades sociales para niños (Inventário Multimídia de Habilidades Sociais para Crianças - IMHSC-Del Prette) a demás de un cuestionario para la evaluación de datos socio demográficos. Participaron 100 niños con edades entre los 07 y 14 años de $1^{\circ}$ a $5^{\circ}$ año de enseñanza básica de un municipio del interior de Rio Grande do Sur. Los resultados evidenciaran diferencia significativa entre los sexos en la media general de los ítems evaluados. Los resultados indican una trayectoria de expansión de las habilidades sociales, visto que los participantes de 10 años o más demostraron ser más hábiles socialmente que los de 7. Los resultados resaltan la importancia de las habilidades sociales en la infancia, visto que el desarrollo de las mismas pueden actuar como factor de protección al desarrollo psicosocial de los niños.

Palabras clave: Habilidades sociales, infancia, prevención.

O conceito de habilidades sociais (HS) está relacionado às características dos comportamentos das pessoas, inseridos em nossa cultura, definindo valores e normas que influenciam nas formas de nos relacionarmos. Existem algumas controvérsias acerca da definição de um comportamento hábil, desta forma, as HS devem ser consideradas dentro de um contexto social, histórico e cultural, e são relativas aos padrões de comunicação de cada cultura. O comportamento socialmente hábil é um conjunto de comportamentos emitidos por um indivíduo em um contexto interpessoal que expressa sentimentos, atitudes, desejos, opiniões ou direitos desse indivíduo de modo adequado à situação, respeitando esses comportamentos nos demais, e que geralmente resolve os problemas imediatos da situação enquanto minimiza a probabilidade de futuros problemas (Caballo, 2012).

Segundo Del Prette e Del Prette (2011b) pode-se definir o conceito de HS como diferentes classes de comportamento social que um indivíduo possui, as mesmas contribuem para a competência social e para um desenvolvimento saudável com outras pessoas, pois possibilita um grau maior de comunicação e interação. Já a competência social apresenta um caráter avaliativo que irá se definir pela coerência e funcionalidade do desempenho social e pode ser entendida como a capacidade de organizar pensamentos, sentimentos e comportamentos, atendendo as demandas do ambiente social; a competência social influencia diretamente o desempenho acadêmico (Cia \& Barham, 2009; Welsh, Parke, Widaman, \& O'Neil, 2001).

Algumas classes de HS são entendidas, apesar da análise do repertório social na infância ainda ser bastante escassa, como prioritárias no desenvolvimento interpessoal da criança: Autocontrole e expressividade emocional; Civilidade; Empatia; Assertividade; Fazer amizades; Solução de problemas interpessoais e Habilidades sociais acadêmicas. As HS são mais que comportamentos sociais classificados como boas maneiras. No decorrer do processo de desenvolvimento a criança torna-se mais competente à medida que passa a assimilar normas, valores e expectativas de seu ambiente (Del Prette \& Del Prette, 2011b).

A literatura não afirma precisamente a etapa do ciclo vital em que ocorre o desenvolvimento das HS e habilidades específicas para conduzir a execução competente de uma tarefa, mas estima-se que a infância seja um período mui- 
to importante (Bartholomeu, Silva, \& Montiel, 2011). Segundo Berry e O'Connor (2010), as HS têm trajetórias de expansão, porém ressaltam que é possível observar ao decorrer do desenvolvimento, períodos de aceleração acentuada nos primeiros anos escolares e depois desaceleração nos anos finais.

$\mathrm{O}$ ingresso escolar assume grande importância na vida da criança sendo principalmente um marco da extensão do convívio social para além da família, evidenciando um caráter crítico para a aquisição de conhecimentos e habilidades que se desenvolvem para a vida adulta formando uma base que irá determinar os futuros sucessos ou fracassos (Papalia, Olds, \& Feldman, 2010). A adesão da criança ao ambiente escolar vai demandar uma adaptação às novas regras, diferente das do contexto familiar e, supõe-se que a criança, a partir dessa inserção, amplie e aprimore seu repertório de HS, contribuindo para uma melhor adaptação e estabelecimento de relações harmoniosas, podendo prevenir o aparecimento de comportamentos agressivos (Bandeira, Del Prette, Del Prette, \& Magalhaes, 2009).

Segundo Bolsoni-Silva, Mariano, Loureiro e Bonaccorsi (2013), os professores incentivam bons comportamentos dos alunos e os mesmos demonstram contentamento. Em contrapartida, os comportamentos desaprovados pelos professores geram comportamentos agressivos e insatisfatórios nos alunos. Sendo assim, as práticas positivas do professor na promoção de HS e na redução de problemas comportamentais, vêm assumindo grande importância dentro do contexto escolar.

Alguns estudos vêm mostrando que existem diferenças em relação às HS e as variáveis sexo, nível socioeconômico e idade, bem como as consequências comportamentais ligadas a baixos escores de HS. Dentre as consequências, pode-se destacar o aparecimento de comportamentos antissociais e agressivos, dificuldades de aprendizagem e isolamento social (Bolsoni-Silva, Marturano, \& Freiria, 2010; Pizato, Marturano, $\&$ Fontaine, 2014).

Diante da relevância da infância e da inserção no contexto escolar para o desenvolvi- mento e aprimoramento das HS, levando em consideração os resultados obtidos em estudos nessa área, faz-se importante identificar esse repertório nas crianças, visando um enfoque preventivo, trabalhando com aspectos saudáveis e possibilitando um olhar voltado ao sujeito antes do aparecimento do problema (Almeida, 2012). Este estudo teve como objetivo identificar quais as habilidades sociais presentes em crianças inseridas no contexto escolar e mensurar a relação com variáveis sociodemográficas (sexo, idade e nível socioeconômico).

\section{Método}

Trata-se de uma pesquisa quantitativa de caráter descritivo-exploratório (Gil, 2010).

\section{Participantes}

Os participantes foram 100 alunos de escolas públicas da rede estadual e municipal em uma cidade do interior do RS com idade variando de 7 a 14 anos, sendo a média de 9,2 $(D P \pm 1,4)$ anos e foram excluídas da pesquisa crianças não alfabetizadas e com 7 anos incompletos até a data da finalização da coleta de dados.

\section{Instrumentos}

Para a coleta de dados foi utilizado o Inventário Multimídia de Habilidades Sociais para Crianças - IMHSC - Del-Prette (Del Prette \& Del Prette, 2005). O inventário está aprovado pelo Conselho Federal de Psicologia (CFP) desde 2005 e consiste em um sistema de avaliação de HS composto por materiais impressos e digitais para a avaliação individual ou coletiva, de crianças ingressas no ensino fundamental, com idade de 07 a 12 anos. Foi utilizada a versão informatizada do instrumento e a aplicação foi realizada coletivamente. A versão informatizada do IMHSC - Del-Prette (2005) contém 21 itens os quais apresentam situações e reações do cotidiano escolar em interação com outras crianças e adultos. Diante disso, são disponibilizadas três escolhas de reação: habilidosa, não habilidosa passiva e não habilidosa ativa. A criança 
deve então assinalar a reação que ela teria para a situação apresentada, essas interações abrangem situações nas quais os participantes devem colocar-se no lugar do outro (Del Prette \& Del Prette, 2005). Segundo os autores, o instrumento permite agrupar os itens avaliados em 4 subescalas: Empatia e civilidade; Assertividade de enfrentamento; Autocontrole e Participação. As definições para esses conceitos correspondem as capacidades citadas abaixo:

- Empatia e civilidade: habilidades de expressão de sentimentos positivos de solidariedade e companheirismo ou de polidez social, por exemplo, fazer e agradecer elogios, oferecer ajuda e pedir desculpas;

- Assertividade de enfrentamento: habilidades de afirmação e defesa dos direitos e de autoestima, com risco potencial de reação indesejável (maior probabilidade de rejeição, de réplica ou de oposição) por parte do interlocutor, por exemplo, solicitar mudança de comportamento do outro, defender-se de acusações injustas e resistir à pressão do grupo;

- Autocontrole: habilidades que envolvem controle emocional diante de frustração ou de reação negativa ou indesejável de colegas, por exemplo, recusar pedido de colega, demonstrar espírito esportivo e aceitar brincadeiras;

- Participação: habilidade de envolver-se e comprometer-se com o contexto social mesmo quando as demandas do ambiente não lhe são especificamente dirigidas, por exemplo, responder às perguntas da professora, mediar conflitos entre os colegas e juntar-se a um grupo em brincadeiras.

A consistência interna do instrumento, obtida a partir do Alpha de Cronbach foi de 0,64 para frequência e de 0,69 para dificuldade (Del Prette \& Del Prette, 2002). Foi aplicado também um questionário sociodemográfico para identificar sexo, idade, entre outros, avaliando os critérios de inclusão e exclusão mencionados acima. Também foi utilizada a Ficha de Avaliação Socioeconômica baseada no Critério Brasil (Associação Brasileira de Empresas de Pesquisa [ABEP], 2013).

\section{Procedimentos Éticos e de Coleta de Dados}

O presente trabalho foi aprovado pelo Comitê de Ética em Pesquisa da Universidade do Vale do Rio dos Sinos (UNISINOS), sob o número CEP 14/036 e atendeu as exigências éticas previstas na resolução $n^{\circ} 466 / 12$ (Conselho Nacional de Saúde [CNS], 2012), que discorre sobre a realização de pesquisas com seres humanos. Todos os participantes e responsáveis concordaram e assinaram o Termo de Consentimento Livre e Esclarecido contendo os objetivos desta pesquisa. Os dados coletados foram armazenados e serão mantidos por, no mínimo, cinco anos de acordo com exigências legislativas vigentes. A coleta de dados iniciou em Junho de 2014, após a aprovação do projeto pelo Comitê de Ética em Pesquisa da UNISINOS. Para a coleta de dados foi realizado contato telefônico com três escolas públicas, sendo duas da rede municipal e uma da rede estadual de um município do interior do Rio Grande do Sul, através do critério de conveniência. Na oportunidade, foi exposta brevemente a proposta da pesquisa, com as escolas que concordaram em participar, foi agendado um encontro para apresentação integral do projeto à equipe diretiva e professores, explicitando seus objetivos e procedimentos éticos. Por se tratar de pesquisa com crianças foi necessária a autorização dos pais e/ou responsáveis para que os mesmos pudessem participar da pesquisa. Sendo assim, o projeto foi apresentado em uma linguagem compreensível para as crianças. As que concordaram em participar da pesquisa levaram para os pais e/ou responsáveis uma apresentação do projeto, o Termo de Consentimento Livre e Esclarecido (TCLE) que foi assinado em duas vias pelos pais e/ou responsáveis e pelas crianças que concordaram quanto a sua participação na pesquisa, e também os questionários sociodemográfico e socioeconômico. Posteriormente ao prazo estabelecido para o retorno da documentação, foi agendado um horário para a aplicação coletiva do instrumento de avaliação, que teve duração aproximada de uma hora e quinze minutos. A aplicação aconteceu em horário de aula, 
em sala com condições favoráveis a aplicação, com recursos de vídeo e áudio e acomodações para os alunos.

\section{Procedimentos de Análise dos Dados}

A apresentação dos resultados ocorreu pela estatística descritiva através da distribuição absoluta e relativa ( $n-\%)$, bem como, através da média, desvio padrão e amplitude, com o estudo da simetria das distribuições pelo teste de Kolmogorov-Smirnov. Para a análise bivariada sobre as variáveis contínuas, quando a comparação ocorreu entre dois grupos independentes foi aplicado o teste $t$-Student, e quando a comparação ocorreu entre três grupos ou mais foi utilizada a Análise de Variância (One Way) - Post Hoc Tukey. Os dados receberam tratamento estatístico utilizando-se o software SPSS 17.0 (Statistical Package to Social Sciences for Windows) onde, para critérios de decisão foi adotado o nível de significância de 5\%.

\section{Resultados}

Caracterizando os participantes da pesquisa, a maioria tinha 10 anos ou mais, $32,0 \%(n=32)$ $\mathrm{e}$, sobre as demais faixas de idade estas se mantiveram aproximadamente na proporção de $20 \%$. $\mathrm{O}$ sexo feminino mostrou-se ligeiramente mais elevado, $52,0 \%$ ( $n=52)$ que o masculino, $48,0 \%$ $(n=48)$. Considerando as séries que estavam sendo cursadas no momento da investigação, as maiores frequências foram para o $3^{\circ}$ ano, $26,0 \%$ $(n=26)$, bem como para o $1^{\circ}$ e $5^{\circ}$ anos, cada um representando $23,0 \%(n=23)$ da amostra.

Sobre o nível socioeconômico, a maior frequência foi para a classe $\mathrm{B} 2,31,0 \%(n=31)$, seguidas das classes $\mathrm{B} 1,24,0 \%(n=24)$, e $\mathrm{C} 1,22 \%$ $(n=22)$. Ainda observaram-se 6 casos $(6,0 \%) \mathrm{em}$ que o nível socioeconômico não foi informado.

Os resultados (pontuação média geral e subescalas) do instrumento IMHSC - Del-Prette (Del Prette \& Del Prette, 2005) foram comparados às variáveis que caracterizaram o perfil dos investigados. Na comparação em relação ao sexo, foi detectada diferença estatística significativa $(p=0,028)$ na pontuação média geral, apontando que o sexo feminino apresentou média mais elevada quando comparado ao sexo masculino. Nas subescalas os resultados foram semelhantes, ou seja, médias mais elevadas podem ser observadas no sexo feminino, no entanto, a diferença significativa se configurou nas subescalas empatia-civilidade $(p=0,009)$ e autocontrole $(p=0,016)$; indicando que, nesta pesquisa, conforme Tabela 1, que o sexo feminino é mais empático-civil e possui maior autocontrole em comparação com o sexo masculino.

Tabela 1

Média e Desvio Padrão para as Subescalas Segundo o Sexo

\begin{tabular}{lccccc}
\hline & \multicolumn{5}{c}{ Sexo } \\
\cline { 2 - 5 } \multicolumn{1}{c}{ Escalas } & \multicolumn{2}{c}{ Feminino (52) } & \multicolumn{2}{c}{ Masculino (48) } & $p \S$ \\
\cline { 2 - 5 } & Média & $D P$ & Média & $D P$ & \\
\hline Média geral & $\mathbf{1 , 6 5}$ & 0,23 & 1,50 & 0,43 & $\mathbf{0 , 0 2 8}$ \\
Empatia-civilidade & $\mathbf{1 , 8 2}$ & 0,20 & 1,62 & 0,51 & $\mathbf{0 , 0 0 9}$ \\
Assertividade & 1,46 & 0,39 & 1,35 & 0,44 & 0,221 \\
Autocontrole & $\mathbf{1 , 6 5}$ & 0,28 & 1,45 & 0,52 & $\mathbf{0 , 0 1 6}$ \\
Participação & 1,71 & 0,39 & 1,58 & 0,53 & 0,189 \\
\hline
\end{tabular}

Nota. §: Teste $t$-Student para grupos independentes. Negrito: Referem-se a médias mais elevadas na comparação entre os sexos feminino e masculino.

Sobre a análise comparativa do instrumento em relação a faixa etária, ocorreu diferença significativa para a pontuação média geral
( $p=0,001)$, indicando que, os investigados com 10 anos ou mais apresentaram pontuação média mais elevada que o grupo de 7 anos $(p<0,01)$, 
mas não diferiu das faixas de 8 anos $(p=0,103) \mathrm{e}$ de 9 anos $(p=0,078)$.

Em relação às subescalas, a diferença significativa para a empatia-civilidade $(p=0,008)$, indicou que o grupo com 10 anos ou mais apresentou pontuação média significativamente mais elevada, quando comparada ao grupo de 7 anos $(p<0,01)$, mas sem diferenças expressivas com as faixas de idade de 8 anos $(p=0,277)$ e de 9 anos $(p=0,464)$. Resultados semelhantes ocorreram nas subescalas da assertividade (10 anos ou mais VS 9 anos: $p=0,387$ / 8 anos: $p=0,355 / 7$ anos: $p=0,017$ ); e autocontrole ( 10 anos ou mais
$V S 9$ anos: $p=0,011 / 8$ anos: $p=0,208 / 7$ anos: $p=0,009$ ).

A subescala da participação não apresentou diferenças expressivas em relação à idade, conforme Tabela 2 .

Quando realizada a comparação do IMHSC - Del-Prette (2005) em relação à série de estudo, foram detectadas diferenças estatísticas sobre as pontuações médias, tanto na pontuação geral $(p<0,001)$, quanto sobre as subescalas da empatia-civilidade $\quad(p<0,001) ; \quad$ assertividade $(p=0,007)$; e autocontrole $(p<0,001)$. As diferenças detectadas apontaram que as pontuações

Tabela 2

Média e Desvio Padrão para a Pontuação Média Geral e Subescalas Segundo a Faixa Etária

\begin{tabular}{|c|c|c|c|c|c|c|c|c|c|}
\hline \multirow{3}{*}{ Escalas } & \multicolumn{9}{|c|}{ Faixa etária (anos) } \\
\hline & \multicolumn{2}{|c|}{$7(n=24)$} & \multicolumn{2}{|c|}{$8(n=21)$} & \multicolumn{2}{|c|}{$9(n=23)$} & \multicolumn{2}{|c|}{10 ou mais $(n=32)$} & \multirow{2}{*}{$p ¥$} \\
\hline & Média & $D P$ & Média & $D P$ & Média & $D P$ & Média & $D P$ & \\
\hline Média geral & $1,36 \mathrm{~b}$ & 0,51 & $1,62 \mathrm{ab}$ & 0,25 & $1,59 b$ & 0,24 & $1,71 \mathrm{a}$ & 0,23 & 0,001 \\
\hline Empatia-civilidade & $1,49 b$ & 0,64 & $1,79 b$ & 0,25 & $1,76 b$ & 0,28 & $1,84 \mathrm{a}$ & 0,21 & 0,008 \\
\hline Assertividade & $1,21 b$ & 0,47 & $1,44 \mathrm{ab}$ & 0,37 & $1,43 \mathrm{ab}$ & 0,33 & $1,53 \mathrm{a}$ & 0,43 & 0,043 \\
\hline Autocontrole & $1,26 b$ & 0,58 & $1,61 \mathrm{ab}$ & 0,30 & $1,52 b$ & 0,34 & $1,76 \mathrm{a}$ & 0,25 & $<0,001$ \\
\hline Participação & 1,51 & 0,64 & 1,73 & 0,40 & 1,62 & 0,43 & 1,71 & 0,35 & 0,351 \\
\hline
\end{tabular}

Nota. ¥: Análise de variância OneWay - Post Hoc Tukey, médias seguidas de letras iguais na linhas não diferem a 5\% de significância, $a=$ média significativamente maior; $b=$ segunda média significativamente maior; $a b=$ média onde constam as duas letras não difere das outras médias onde contam as letras "a" e letra "b".

Tabela 3

Média e Desvio Padrão para a Pontuação Média Geral e Subescalas em Relação a Série de Estudo

\begin{tabular}{|c|c|c|c|c|c|c|c|c|c|c|c|}
\hline \multirow{3}{*}{ Escalas } & \multicolumn{11}{|c|}{ Série } \\
\hline & \multicolumn{2}{|c|}{$1^{\mathrm{a}}$ ano $(n=9)$} & \multicolumn{2}{|c|}{$2^{\mathrm{a}}$ ano $(n=23)$} & \multicolumn{2}{|c|}{$3^{\mathrm{a}}$ ano $(n=26)$} & \multicolumn{2}{|c|}{$4^{\mathrm{a}}$ ano $(n=19)$} & \multicolumn{2}{|c|}{$5^{\mathrm{a}}$ ano $(n=13)$} & \multirow{2}{*}{$p ¥$} \\
\hline & Média & $D P$ & Média & $D P$ & Média & $D P$ & Média & $D P$ & Média & $D P$ & \\
\hline Média geral & $1,07 b$ & 0,64 & $1,52 \mathrm{ab}$ & 0,32 & $1,66 \mathrm{ab}$ & 0,24 & $1,60 \mathrm{ab}$ & 0,19 & $1,73 \mathrm{a}$ & 0,25 & $<0,001$ \\
\hline Empatia-civilidade & $1,08 b$ & 0,82 & $1,71 \mathrm{a}$ & 0,31 & $1,83 \mathrm{a}$ & 0,26 & $1,78 \mathrm{a}$ & 0,19 & $1,84 \mathrm{a}$ & 0,24 & $<0,001$ \\
\hline Assertividade & $0,96 b$ & 0,56 & $1,35 \mathrm{a}$ & 0,36 & $1,47 \mathrm{a}$ & 0,32 & $1,47 \mathrm{a}$ & 0,34 & $1,52 \mathrm{a}$ & 0,47 & $\mathbf{0 , 0 0 7}$ \\
\hline Autocontrole & $1,03 c$ & 0,70 & $1,45 b$ & 0,43 & $1,61 \mathrm{a}$ & 0,33 & $1,54 \mathrm{a}$ & 0,28 & $1,82 \mathrm{a}$ & 0,22 & $<0,001$ \\
\hline Participação & 1,30 & 0,81 & 1,65 & 0,49 & 1,76 & 0,37 & 1,54 & 0,37 & 1,74 & 0,36 & 0,70 \\
\hline
\end{tabular}

Nota. ¥: Análise de variância OneWay - Post Hoc Tukey, onde médias seguidas de letras iguais na linhas não diferem a 5\% de significância. Negrito: Referem-se as diferenças estatísticas significativas encontradas na comparação das médias dos demais anos de estudo.

$\mathrm{a}=$ média significativamente maior; $\mathrm{b}=$ segunda média significativamente maior; $\mathrm{c}=$ média significativamente menor; $\mathrm{ab}=$ média onde constam as duas letras não difere das outras médias onde contam as letras "a" e letra "b". 
médias dos investigados do $1^{\circ}$ ano mostraram-se significativamente menores quando comparadas as médias dos demais anos de estudo. Sobre a subescala da participação, as diferenças significativas não se configuraram, indicando que, esta subescala independe dos anos de estudo nesta amostra, conforme Tabela 3.

Quando a pontuação média geral e as subescalas do IMHSC - Del-Prette (2005) foram comparadas a classe social, não ocorreram diferenças significativas, conforme Tabela 4.

Tabela 4

Média e Desvio Padrão para a Pontuação Média Geral e Subescalas Segundo a Classe Social

\begin{tabular}{|c|c|c|c|c|c|c|c|c|c|}
\hline \multirow{3}{*}{ Escalas } & \multicolumn{9}{|c|}{ Classe social } \\
\hline & \multicolumn{2}{|c|}{$\mathrm{A}(1$ e 2$)(n=13)$} & \multicolumn{2}{|c|}{$\mathrm{B} 1(n=24)$} & \multicolumn{2}{|c|}{$\mathrm{B} 2(n=31)$} & \multicolumn{2}{|c|}{$\mathrm{C}(1$ e 2$)$ e $\mathrm{D}(n=26)$} & \multirow{2}{*}{$p \S$} \\
\hline & Média & $D P$ & Média & $D P$ & Média & $D P$ & Média & $D P$ & \\
\hline Média geral & 1,53 & 0,47 & 1,57 & 0,34 & 1,52 & 0,40 & 1,66 & 0,21 & 0,500 \\
\hline Empatia-civilidade & 1,62 & 0,58 & 1,70 & 0,41 & 1,70 & 0,42 & 1,83 & 0,24 & 0,392 \\
\hline Assertividade & 1,42 & 0,47 & 1,43 & 0,40 & 1,34 & 0,48 & 1,44 & 0,37 & 0,817 \\
\hline Autocontrole & 1,52 & 0,53 & 1,50 & 0,44 & 1,51 & 0,46 & 1,67 & 0,25 & 0,404 \\
\hline Participação & 1,64 & 0,48 & 1,63 & 0,45 & 1,56 & 0,56 & 1,76 & 0,35 & 0,474 \\
\hline
\end{tabular}

Nota. ¥: Análise de variância OneWay - Post Hoc Tukey.

\section{Discussão}

Os resultados desta pesquisa mostram que as meninas apresentaram desempenho melhor em relação aos meninos quanto a comportamentos socialmente habilidosos, bem como nas subescalas empatia-civilidade e autocontrole. Uma pesquisa realizada por Del Prette e Del Prette (2002) não encontrou diferenças em relação ao sexo em sua pesquisa, entretanto, outras pesquisas ressaltam diferenças, mostrando que as meninas apresentaram uma maior frequência de HS e comportamentos positivos que os meninos (Bandeira et al., 2009; Gardinal \& Marturano, 2007; Sallquist et al., 2009).

Sallquist et al. (2009) menciona que os professores tendem a esperar que meninas demonstrem mais comportamentos socialmente habilidosos e os meninos mais comportamentos perturbadores, ou seja, menos habilidosos, fazendo relação desses comportamentos a maior autorregulação presente em meninas. Pode-se compreender a autorregulação como um mecanismo que oferece condições de monitoramento, avaliação e controle do comportamento, direcionando o indivíduo aos seus objetivos pessoais, além de conceber o papel ativo do indivíduo no qual são também autoexaminadoras de seu processo cognitivo, afetivo e comportamental. Sendo assim, os indivíduos utilizam suas estratégias autorreguladoras para obter satisfação e bem-estar, privando-se de comportamentos que conduzam à autocensura (Bandura, Azzi, \& Polydoro, 2008).

Cecconello e Koller (2000) em seu estudo tiveram por objetivo avaliar a competência social e a empatia em crianças escolares que vivem em situação de pobreza. Participaram desse estudo cem crianças do primeiro ao terceiro ano, sendo que a distribuição por sexo foi semelhante. Os resultados dessa pesquisa encontraram dados que revelam diferenças entre os sexos, apontando que as meninas são mais empáticas que os meninos. Em outro estudo que objetivou verificar a relação entre empatia e agressividade foi ressaltada a importância da empatia para um desenvolvimento saudável. Os déficits nessa área foram considerados fatores de risco para comportamentos antissociais e agressivos, apontando a importância de programas preventivos e de promoção de comportamentos habilidosos (Pavarino, Del Prette, \& Del Prette, 2005). 
As HS têm trajetórias de expansão conforme indicam estudos longitudinais, corroborando os achados neste estudo que demonstrou que os participantes com 10 anos ou mais foram mais habilidosos socialmente que os de 7 anos, porém, os participantes de 10 anos ou mais não diferiram dos participantes de 8 e 9 anos. Berry e O'Connor (2010) analisaram as trajetórias de crescimento de HS do jardim de infância até a $6^{\mathrm{a}}$ série e os resultados apontaram a expansão, ou seja, o crescimento ao longo dos anos. Porém, encontram períodos de aceleração acentuada nos primeiros anos escolares e depois desaceleração nos anos. Em contrapartida, o estudo de Sallquist et al. (2009) aponta modesta redução no ensino fundamental de comportamentos socialmente habilidosos, inicialmente avaliados na educação infantil.

As diferenças encontradas nos estudos longitudinais acima citados podem estar relacionadas a diversos fatores, entre eles, a diferença metodológica adotada em cada estudo, sendo que as HS não foram avaliadas de forma a mensurar uma mesma variável nos diferentes contextos de avaliação. No estudo de Berry e O'Connor (2010), por exemplo, as mães realizaram uma avaliação das HS da criança e a qualidade da relação professor-aluno também fez parte do estudo, sendo avaliada pelo professor. No estudo de Sallquist et al. (2009) os comportamentos sociais e emocionais dos participantes foram avaliados pelos cuidadores primários e os professores responderam questionários de natureza semelhante.

Bandeira et al. (2009) além das diferenças em relação ao sexo, encontraram em sua pesquisa diferença em relação ao nível socioeconômico, quanto mais elevado o nível socioeconômico maior os escores de HS, contrapondo os dados encontrados nesta pesquisa que não foram encontradas diferenças quando as $\mathrm{HS}$ foram correlacionadas ao nível socioeconômico. Esse resultado pode ser explicado pelo fato da maior frequência da amostra ter se concentrado entre as classes B e C, com menor amostra para as classes A e D, sendo assim os participantes da pesquisa pertenciam a classes econômicas que pouco diferem entre si, podendo este fator ter influenciado um resultado divergente ao das pesquisas existentes até o momento.

\section{Considerações Finais}

Este trabalho apresentou como temática central as HS na infância objetivando a realização de uma pesquisa para identificar quais as HS presentes em crianças inseridas no contexto escolar, de 7 a 12 anos, de escolas públicas da rede municipal e estadual. A partir dos resultados, pode-se observar que o estudo aponta para diferenças consideráveis na variável sexo, sendo que o sexo feminino apresentou uma pontuação, significativamente mais elevada, na média geral, considerando as subescalas avaliadas (empatia-civilidade, assertividade, autocontrole e participação) que o sexo masculino. Quanto ao nível socioeconômico dos participantes, a pesquisa gerou resultados sugestivos, não encontrando diferença nesta amostra.

Para propor intervenções nesta área, podemos pensar em práticas no âmbito de promoção e desenvolvimento das habilidades sociais. A área de Treinamento de Habilidades Sociais (THS) vem sendo amplamente estudada, e segundo Del Prette e Del Prette (2011a, p. 37), "possui três objetivos conceituais importantes: a) promover aquisição de habilidades; b) aperfeiçoar o desempenho da habilidade e c) remover ou reduzir problemas de comportamentos concorrentes". No âmbito do treinamento de habilidades sociais foram realizadas intervenções em sala de aula com duração de sessenta horas. Participaram dessa intervenção estudantes que apresentavam déficits de aquisição de habilidades sociais e observou-se, ao final da intervenção, uma redução nos comportamentos problemáticos (Gresham, Van, \& Cook, 2006).

Reitera-se a importância de um projeto para que a mesma possa ser contemplada nas escolas, desde a educação infantil, visto que a escola assume um importante papel na prevenção e promoção de saúde em crianças. Também se faz necessário dispensar maior atenção em relação ao sexo e buscar o desenvolvimento e aprimo- 
ramento das HS no sexo masculino, o qual apresentou média geral significativamente inferior ao feminino.

Essa pesquisa limitou-se a autoavaliação das HS realizadas pela criança por questões temporais, talvez seja importante contemplar em avaliações futuras, além do contexto escolar, demais contextos nos quais a criança está inserida para que se possa ter um panorama minucioso das HS e suas possíveis variações nos diferentes contextos, como a percepção dos professores, dos pais e mães em relação ao repertório social da criança.

Sendo assim, os resultados obtidos com o trabalho têm implicações no âmbito do desenvolvimento de políticas públicas voltadas para a infância. Também ressaltam a importância das HS nesta fase, visto que desenvolvimento e aquisição das mesmas podem atuar como fator de proteção ao desenvolvimento psicossocial das crianças.

\section{Referências}

Almeida, L. S. (2012). Uma investigação sobre as habilidades sociais de crianças envolvidas no bullying (Dissertação de mestrado, Universidade do Vale do Rio dos Sinos, São Leopoldo, RS, Brasil).

Associação Brasileira de Empresas de Pesquisa. (2013). Alterações na aplicação do Critério Brasil, válidas a partir de 01/01/2013. São Paulo, SP: Autor. Recuperado em http://www.abep. org/Servicos/Download.aspx?id=02

Bandeira, M., Del Prette, Z. A. P., Del Prette, A., \& Magalhaes, T. (2009). Validação das escalas de habilidades sociais, comportamentos problemáticos e competência acadêmica (SSRS-BR) para o ensino fundamental. Psicologia: Teoria e Pesquisa, 25(2), 271-282. doi:10.1590/S010237722009000200016

Bandura, A., Azzi, R. G., \& Polydoro, S. (2008). Teoria social e cognitiva: Conceitos básicos. Porto Alegre, RS: Artmed.

Bartholomeu, D., Silva, M. C. R. da, \& Montiel, J. M. (2011). Teste de habilidades sociais para crianças: Evidências psicométricas de uma versão inicial. Psico-USF, 16(1), 33-43. doi:10.1590/ S1413-82712011000100005
Berry, D., \& O’Connor, E. (2010). Behavioral risk, teacher-child relationship, and social skill development across middle childhood: A childby-environment analysis of change. Journal of Applied Developmental Psychology, 31, 1-14. doi:10.1016/j.appdev.2009.05.001

Bolsoni-Silva, A. T., Mariano, M. L., Loureiro, S. R., $\&$ Bonaccorsi, C. (2013). Contexto escolar: Práticas educativas do professor, comportamento e habilidades sociais infantis. Psicologia Escolar e Educacional, 17(2), 259-269. doi:10.1590/ S1413-85572013000200008

Bolsoni-Silva, A. T., Marturano, E. M., \& Freiria, L. R. B. (2010). Indicativos de problemas de comportamento e de habilidades sociais em crianças: Um estudo longitudinal. Psicologia: Reflexão \& Crítica, 23(3), 506-515. Recuperado em http:// www.scielo.br/pdf/prc/v23n3/11.pdf

Caballo, V. (2012). Manual de avaliação e treinamento de habilidades sociais. São Paulo, SP: Santos.

Cecconello, A. M., \& Koller, S. H. (2000). Competência social e empatia: Um estudo sobre resiliência com crianças em situação de pobreza. Estudos de Psicologia (Natal), 5(1), 71-93. doi:10.1590/ S1413-294X2000000100005

Cia, F., \& Barham, E. J. (2009). Repertório de habilidades sociais, problemas de comportamento, autoconceito e desempenho acadêmico de crianças no início da escolarização. Estudos de Psicologia (Campinas), 26(1), 45-55. doi:10.1590/ S0103-166X2009000100005

Conselho Nacional de Saúde. (2012). Resolução $n^{o}$ 466/12, de 12 de dezembro de 2012. Brasília, DF: Autor. Recuperado em http://conselho.saude.gov.br/resolucoes/2012/Reso466.pdf

Del Prette, Z. A. P., \& Del Prette, A. (2002). Avaliação de habilidades sociais de crianças com um inventário multimídia: Indicadores sociométricos associados a frequência versus dificuldade. Psicologia em Estudo, 7(1), 39-49. doi:10.1590/S1413-73722002000100009

Del Prette, Z. A. P., \& Del Prette, A. (2005). Sistema multimidia de habilidades sociais de crianças (SMHSC). São Paulo, SP: Casa do Psicólogo.

Del Prette, Z. A. P., \& Del Prette, A. (2011a). Psicologia das habilidades sociais: Diversidade teórica e suas implicações (2. ed.). Rio de Janeiro, RJ: Vozes. 
Del Prette, Z. A. P., \& Del Prette, A. (2011b). Psicologia das habilidades sociais na infância: Teoria e prática (5. ed.). Rio de Janeiro, RJ: Vozes.

Gardinal, E. C., \& Marturano, E. M. (2007). Meninos e meninas na educação infantil: Associação entre comportamento e desempenho. Psicologia em Estudo, 12(3), 541-551. doi:10.1590/S141373722007000300011

Gil, A. C. (2010). Como elaborar projetos de pesqui$s a$ (5. ed.). São Paulo, SP: Atlas.

Gresham, F. M., Van, M. B., \& Cook, C. R. (2006). Social skills training for teaching replacement behaviors: Remediating acquisition deficits in at-risk students. Behavioral Disorders, 31(4), 363-377. Retrieved from http://www. researchgate.net/publication/234741599_Social_Skills_Training_for_Teaching_Replacement_Behaviors_Remediating_Acquisition Deficits_in_At-Risk_Students

Papalia, D. E., Olds, S. W., \& Feldman, R. D. (2010). Desenvolvimento humano (10. ed.). Porto Alegre, RS: AMGH.

Pavarino, M. G., Del Prette, A., \& Del Prette, Z. A. P. (2005). O desenvolvimento da empatia como prevenção da agressividade na infância. Psico, 36(2), 127-134. Recuperado em http://revistaseletronicas.pucrs.br/ojs/index.php/revistapsico/ article/viewFile/1382/1082
Pizato, E. C. G., Marturano, E. M., \& Fontaine, A. M. G. (2014). Trajetórias de habilidades sociais e problemas de comportamento no ensino fundamental: Influência da educação infantil. Psicologia: Reflexão \& Crítica, 27(1), 189-197. Recuperado em http://www.scielo.br/pdf/prc/ v27n1/21.pdf

Sallquist, J. V., Eisenberg, N., Spinrad, T. L., Reiser, M., Hofer, C., Liew, J., ...Eggum, N. (2009). Positive and negative emotionality: Trajectories across six years and relations with social competence. Emotion, 9, 15-28. doi:10.1037/a0013970

Welsh, M., Parke, R. D., Widaman, K., \& O’Neill, R. (2001). Linkages Jetween children's social and academic competence: A longitudinal analysis. Journal of School Psychology, 39, 463-482. Retrieved from http://www.sciencedirect.com/science/article/pii/S002244050100084X
Recebido: 03/02/2015

$1^{a}$ revisão: $28 / 07 / 2015$

$2^{a}$ revisão: $21 / 09 / 2015$

Aceite final: 25/09/2015 